\title{
RADIO OBSERVATION OF THE PARTIAL SOLAR EGLIPSE, 20 JUNE 1955
}

T. HAT ANAKA

Tokyo Astronomical Observatory, Mitaka, Tokyo, Japan

The partial solar eclipse of 20 June 1955 was observed at Tokyo and Toyokawa, where regular solar radio observations are conducted. A party was sent to Kagoshima by the Tokyo Astronomical Observatory. The locations, the frequencies observed and the types of aerial are listed in Table I. The paths of the northern limb of the moon at three stations are shown by dotted lines in Fig. 3 .

\begin{tabular}{|c|c|c|c|c|}
\hline \multirow{2}{*}{$\begin{array}{c}\text { Station } \\
\text { (latitude and } \\
\text { longitude) }\end{array}$} & \multicolumn{3}{|c|}{ Table I } & \multirow[b]{2}{*}{ Organization } \\
\hline & $\begin{array}{l}\text { Magnitude } \\
\text { of the } \\
\text { eclipse }\end{array}$ & $\begin{array}{l}\text { Frequency } \\
\text { (Mc./s.) }\end{array}$ & Type of aerial & \\
\hline $\begin{array}{l}\text { Kagoshima } \\
\left(+31^{\circ} 37^{\prime} \text {, E. } 130^{\circ} 32^{\prime}\right)\end{array}$ & $0 \cdot 3^{8}$ & 3000 & 2 metre dish & $\begin{array}{l}\text { Tokyo Astronomical } \\
\text { Observatory }\end{array}$ \\
\hline $\begin{array}{l}\text { Toyokawa } \\
\left(+34^{\circ} 50^{\prime} \text {, E. } 137^{\circ} 22^{\prime}\right)\end{array}$ & $0 \cdot 21$ & 3750 & 2.5 metre dish & $\begin{array}{l}\text { Research Institute of } \\
\text { Atmospherics }\end{array}$ \\
\hline & & 4000 & $\begin{array}{l}\text { Eight } 1.5 \text { metre dish } \\
\text { interferometer }\end{array}$ & \\
\hline $\begin{array}{l}\text { Tokyo } \\
\left(+35^{\circ} 40^{\prime} \text {, E. } 139^{\circ} 33^{\prime}\right)\end{array}$ & $0 \cdot 16$ & 3000 & Io metre dish & $\begin{array}{l}\text { Tokyo Astronomical } \\
\text { Observatory }\end{array}$ \\
\hline
\end{tabular}

The variations of the total flux at three stations are shown by the curves marked $A$ in Fig. I. The observed variations in flux at the three stations show marked differences. These differences are apparently due to the different magnitudes of obscuration at the three stations of an enhanced region at the position of the sunspot group in the southern hemisphere. At Toyokawa the interferometric observation with eight dishes has been continued during the day. Curves $A$ in Fig. 2 give the drift curves before and during the eclipse.

It is possible to determine the location, the size and the brightness distribution of the enhanced region by combining these eclipse curves. The contours for the radio isophotes thus obtained are shown by full lines 

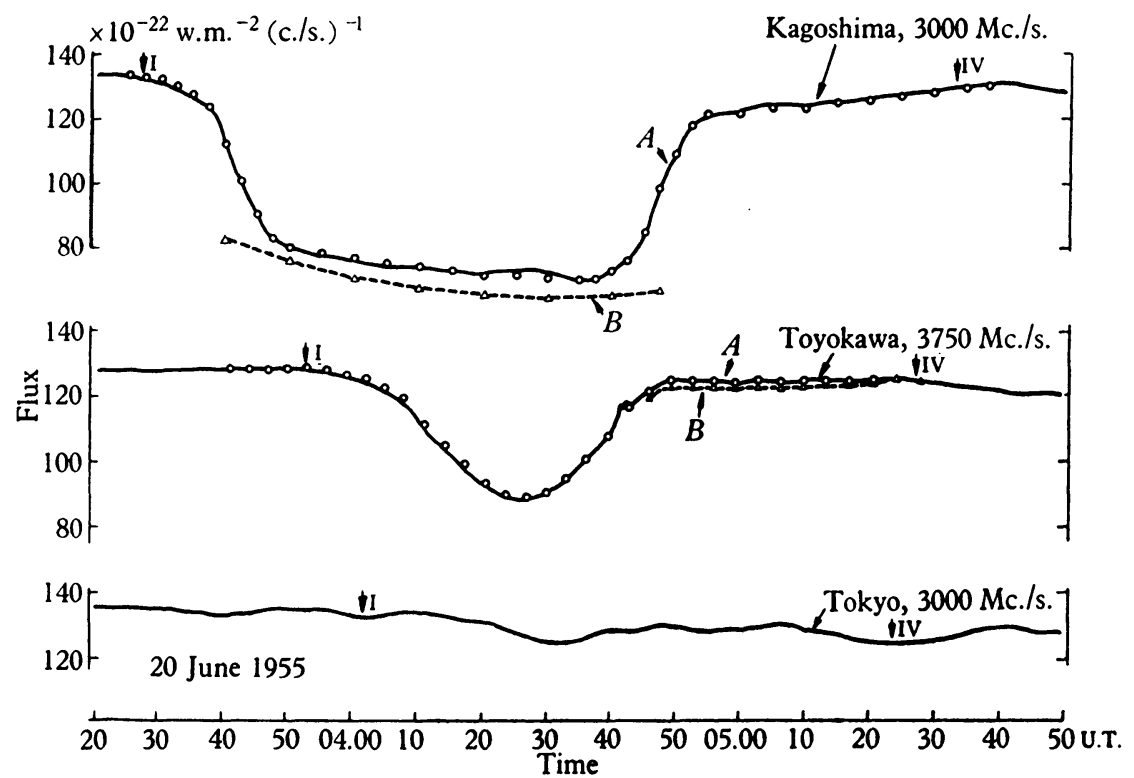

Fig. I. Variation of flux at three stations. Arrows with I and IV indicate the time of the first and fourth contacts.
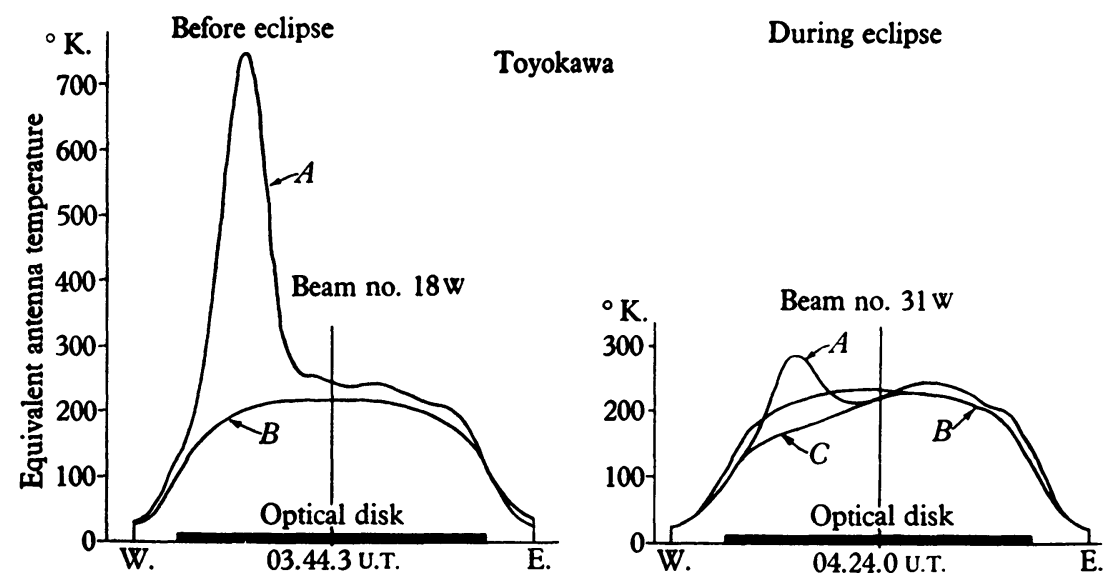

Fig. 2. Drift curves with eight-dish interferometer. $A$, observed curve. $B$, lower envelope of the drift curves observed during June 1955. $C$, calculated drift curve for the basic radiation during the eclipse. 
in Fig. 3. The numbers $I, 2$ and 3 in the figure give the measurements for the relative brightness and roughly correspond to $10^{6 \circ} \mathrm{K}$., $2.10^{6 \circ} \mathrm{K}$. and 3. $10^{6 \circ} \mathrm{K}$. in brightness temperature. The curve in dotted line gives the calcium plage observed at Mount Wilson kindly made available to us by

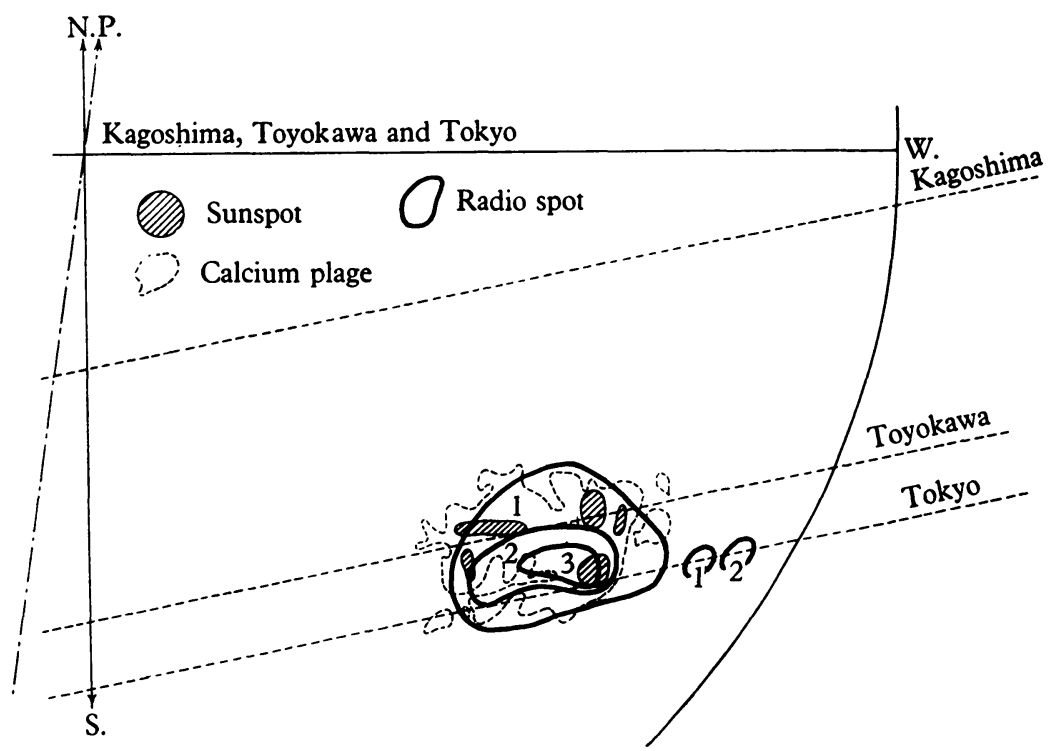

Fig. 3. Comparison between radio and optical observations. Dotted lines indicate the paths of the northern limb of the moon at three stations.

Table 2. (Unit: $\mathrm{IO}^{-22}$ w.m..$^{-2}(\mathrm{c} . / \mathrm{s} .)^{-1}$ )

$\begin{array}{lcc}\text { Source } & \begin{array}{c}\text { Research Institute } \\ \text { of Atmospherics } \\ (3750 \text { Mc./s. })\end{array} & \begin{array}{c}\text { Tokyo Astronomical } \\ \text { Observatory } \\ (3000 \text { Mc./s. })\end{array} \\ \text { Radially symmetric disk } & 62 & 66 \\ \text { Strong radio spot } & 4 \text { I } & 45 \\ \text { Main part } & 38 & 42 \\ \text { Small patch } & 3 & 3 \\ \text { Eastern part } & 4 & 4 \\ \text { Other area } & 2 \mathbf{I} & 20 \\ \text { Total } & 128 & 135\end{array}$

Dr S. B. Nicholson. The close agreement between the radio spot and the calcium plage is very remarkable.

Besides the discussion on the radio spot it was also possible to estimate the contributions to the total flux by the different regions over the solar disk. This estimation was done almost independently by two ways as is shown in Table 2: one by combining the flux observations at Kagoshima 
and Tokyo and the other by combining two observations at Toyokawa. It is found that these two sets of estimations came out very closely to each other. It is to be emphasized that the brightness distribution of the socalled basic radiation cannot be radially symmetric over the solar disk, but only two-thirds of the basic radiation is radially symmetric. (Curves $B$ in Fig. I are the eclipse curves reconstructed on the assumption that the whole basic radiation is radially symmetric.) The remaining one-third is denoted in Table 2 as 'other area'. 'Eastern part' in the table means the contribution by less enhanced regions in the eastern part as judged from the drift curves. The open circles in Fig. I show the reconstructed eclipse curve based on the present conclusion.

Details will be published elsewhere [1, 2].

\section{REFERENGES}

[1] Hatanaka, T., Akabane, K., Moriyama, F., Tanaka, H. and Kakinuma, T. Rep. Ionosphere Research, Japan, 9, I95, 1955.

[2] Hatanaka, T., Akabane, K., Moriyama, F., Tanaka, H. and Kakinuma, T. Publ. Astr. Soc. Japan, 7, I6r, 1955. 